Portland State University

PDXScholar

Summer 2021

\title{
All Changelings Have Autism: How to Make a Better Book for Autistic Children
}

Nadia L. Hitchcock

Portland State University

Follow this and additional works at: https://pdxscholar.library.pdx.edu/honorstheses

Part of the Children's and Young Adult Literature Commons, and the Graphic Design Commons Let us know how access to this document benefits you.

\section{Recommended Citation}

Hitchcock, Nadia L., "All Changelings Have Autism: How to Make a Better Book for Autistic Children" (2021). University Honors Theses. Paper 1144.

https://doi.org/10.15760/honors.1175

This Thesis is brought to you for free and open access. It has been accepted for inclusion in University Honors Theses by an authorized administrator of PDXScholar. Please contact us if we can make this document more accessible: pdxscholar@pdx.edu. 
All Changelings have Autism

How to make a Better Book for Autistic Children

A Graphic Design Thesis by Nadia Hitchcock 
Abstract

How should a content creator, whether they work in film, literature, or sequential art, approach portrayals of Autistic characters? More specifically, how should these altruistic ideas be translated into a better storybook for Autistic children? This is the challenge that I have addressed with my Graphic Design thesis, by writing and illustrating my own children's picture book. The story itself is a spiritual successor to changeling folktales and the book All Cats Have Asperger's Syndrome (Kathy Hoopman 2006). Though many Autistic people loved Hoopman's book as children, its visual shortcomings and linguistic oversights have marred its intended inclusive, positive message. This plight is not unique to Hoopman's work: carefully researched and executed characters like Rain Man's Raymond have received backlash from the Autistic community. Personally, I attempted to bridge this gap between intent and final product by building it on three pillars: inclusivity, accessibility, and character. By building on these three pillars, his story will speak to Autistic peoples' lived experiences, and share it with a wider, mainstream audience. 
Introduction

Disabled characters have provoked fear and fascination since time immemorial. This is clear in the folk tales and superstitions that developed around disabled children. In Western Europe these often took the form of changeling tales: stories of human children spirited away and replaced by a 'malformed' disabled child. These stories recounted bizarre and cruel methods used to restore their 'true' child, such as drowning the changeling baby or throwing them onto a bed of hot coals. Susan Schon describes how these tales 'helped' parents mourn the birth of a disabled child. She explains that, "as the process of grieving continues, denial phases into guilt, often mingled with anger. In the changeling tales, this anger may be directed at the child in a very physical way. Often it is rationalized into an attempt to either force the changeling to reveal its true nature, or to force the fairy parents to return the original child," (61).

Schon's work mostly focused on visible, physical disabilities, but the abuse that she describes mirrors what Autistic people have had to face through the centuries. The justifications caregivers and parents tell themselves have evolved over the centuries, but the pain they visit on disabled people has not. This is evident in quack experiments carried out on Autistic children, from Hans Asperger's child euthanasia program in Nazi-ruled Vienna (Scheffield),) to children forced to drink bleach or suffer through botched enemas (Zadrozny). Even when these quack theories and conspiracies aren't actively murdering Autistic people, they work to prop up tired fears and stereotypes that further marginalize them.

This phenomenon is so widespread that even media created to be sympathetic to the Autistic experience can fall into the same traps of ignoring or stereotyping disabled 
voices. Despite all of this, Autistic depictions have progressed enormously since the days when disabled children were cast into the fire. This has happened even more ever since the Autism self-advocacy movement has risen, and content creators have started consulting actual Autistic people before making content about their lives and experiences.

This era of self-advocacy and neurodiversity is an ideal time to upend these old changeling folktales and reclaim them for the Autistic community. This is what I aim to do with my thesis, by creating a children's book inspired by changeling folklore. By focusing on inclusivity, accessibility, and character, this book will build on past depictions of Autistic people and offer a nuanced, compassionate depiction of life on the spectrum.

\section{Research Summary}

This project was inspired by the paper "Fairies and the Folklore of Disability: Changelings, Hybrids, and the Solitary Fairy," by Susan Schoon Eberly. Eberly took stock of traditional Western European folktales and superstitions about foundling babies, and compared their depictions to actual diagnoses found in disabled children. Her findings, as stated above, were quite upsetting, as these stories meant to aid grieving parents often justified the abuse or murder of their disabled children.

Despite these horrific trends, these kinds of folktales have endured because of their malleability. Generations of writers and illustrators have re-woven these stories and adapted them to the social causes of their times. Given the increased prominence of the neurodiversity movement and the skills I picked up as a Graphic Design student, I wanted to re-introduce changelings as a concept that can empower Autistic children. 
I started my research by conducting a survey of Autistic adults, and asking them what they thought of media depictions of their disability. The result was frustration and exasperation. While the majority of respondents wanted to see more Autistic characters, they were exhausted from being associated with robotic characters or savant geniuses. One respondent in particular commented that,

"I wish a wider range of autistic people and behaviors were represented. I'm getting tired of the socially awkward savant white boy/young man, even though I'm pretty close to matching that description myself."

Another commented that,

“it's always savants or people who are low functioning. They're always portrayed as the social awkward genius or as a plot device. I'd like more "normal" autistic people. Just people who happen to be autistic."

To clarify, there is nothing inherently bad about portraying higher-needs Autistic people, or showing characters with particular talents. But because this one archetype has been repeated ad nauseum, the mainstream public has never seen the many diverse forms that Autism can take. It explains the exhaustion and exasperation that every Autistic feels after a lifetime of being associated with characters like Rain Man's Raymond (1988). What my respondents wanted more than anything was a more colorful, varied set of characters that reflects the vibrant, fascinating individuals found in real life Autistic communities. By treating Autism as a range of people with vastly different needs and quirks, my book can avoid falling into these same tired clichés. 
My secondary research was much more broad, exploring topics ranging from the folklore associated with disability, pop culture portrayals of Autism, and the common pitfalls and clichés that content creators should avoid. A few common archetypes are the genius savant, the quirky character, and the heavily coded/undiagnosed character (Prochnow 133). Often these characters act as magical solutions or devices to solve the protagonist's problems, while having little to no characterization or agency of their own. This kind of portrayal was made famous with the character Raymond from Rain Man, who was sidelined by his brother's goals and schemes throughout the film (Prochnow 135). While not as monstrous as the old tales of fairy children, the fame and mainstream appeal of these narratives have propped up these unfortunate tropes to audiences across the planet.

Despite mistakes made by content creators over the years, the articles I read continually stressed the importance of portraying disabled people. Even children's books carry an enormous responsibility when their authors choose how to present different characters and their interactions. Researcher Ashley Pennell and her colleagues remark how inclusive stories can mirror their own experiences or offer windows into other peoples' lives (Pennell et al). Finding compelling fiction is especially important for Autistic people, who often struggle to communicate with others. For them, a well-spun story is more than just entertainment-it can offer a glimpse into their lives and encourage empathy and acceptance. 
With my research completed, I decided to build my story on three pillars that could improve on past portrayals: inclusivity, accessibility, and character.

Inclusivity means that I want to represent people from across the Autism spectrum and from many different backgrounds. Even though I'm representing Autistic people with changelings instead of humans, I've designed characters with different skin tones, types of hair, heights, body types, and ways of dressing and behaving. This approach to inclusivity will affect the narrative's language choices as well. I will avoid using binary pronouns and use "they/them" instead to refer to the changeling characters. I've also chosen to use disability first language (Autistic people) instead of person first language (people with Autism), as I have throughout this paper. In the self advocacy and neurodiversity movement this is the preferred format of address, as disabled see this as a way to accept their identities without hiding or masking them.

Accessibility means that the book will be laid out and typeset with a disabled, Autistic audience in mind. Autistic people tend to be very sensitive, and are easily overwhelmed by overcrowded page layouts or overly decorative typefaces. To keep this information legible for my target audience, I'm going to use a very simple two-column layout for each page, with a sans-serif typeface for the body copy. It is fairly plain and not terribly innovative, but in my view it is the best way to meet an Autistic audience's needs.

Character means the visual direction inspired by folklore that gives this book its unique identity. This is a retelling of a changeling folktale, and I want to retain some of those fantasy elements in both the design and the storytelling. To reflect this, I've created a wide cast of changelings, humans and other fantasy characters, and set their 
story and a mysterious, overgrown version of the Pacific Northwest. The setting is vaguely apocalyptic, and l've done this to hint at a brighter, kinder future that could exist after a time of upheaval or calamity.

Development

To keep the look of the book consistent, I spent weeks sketching, cobbling together moodboards, and making experimental illustrations to achieve the look that I wanted for the changelings, side characters, and the world that they inhabited. I chose to render these images digitally to help maintain this regularity and to hopefully streamline the illustration process.

Instead of creating one character to try and embody every trait of the Autism Spectrum, I featured a wide range of characters that each have their own quirks and traits. Some are verbal and highly active, while some are more withdrawn and use devices to communicate. Though still limited, I hope that this can provide a window onto the diversity of behaviors and backgrounds that exist in real Autistic communities. After creating the changelings I added side characters to create the idea that these disabled people exist in a community. 
Hitchcock 8
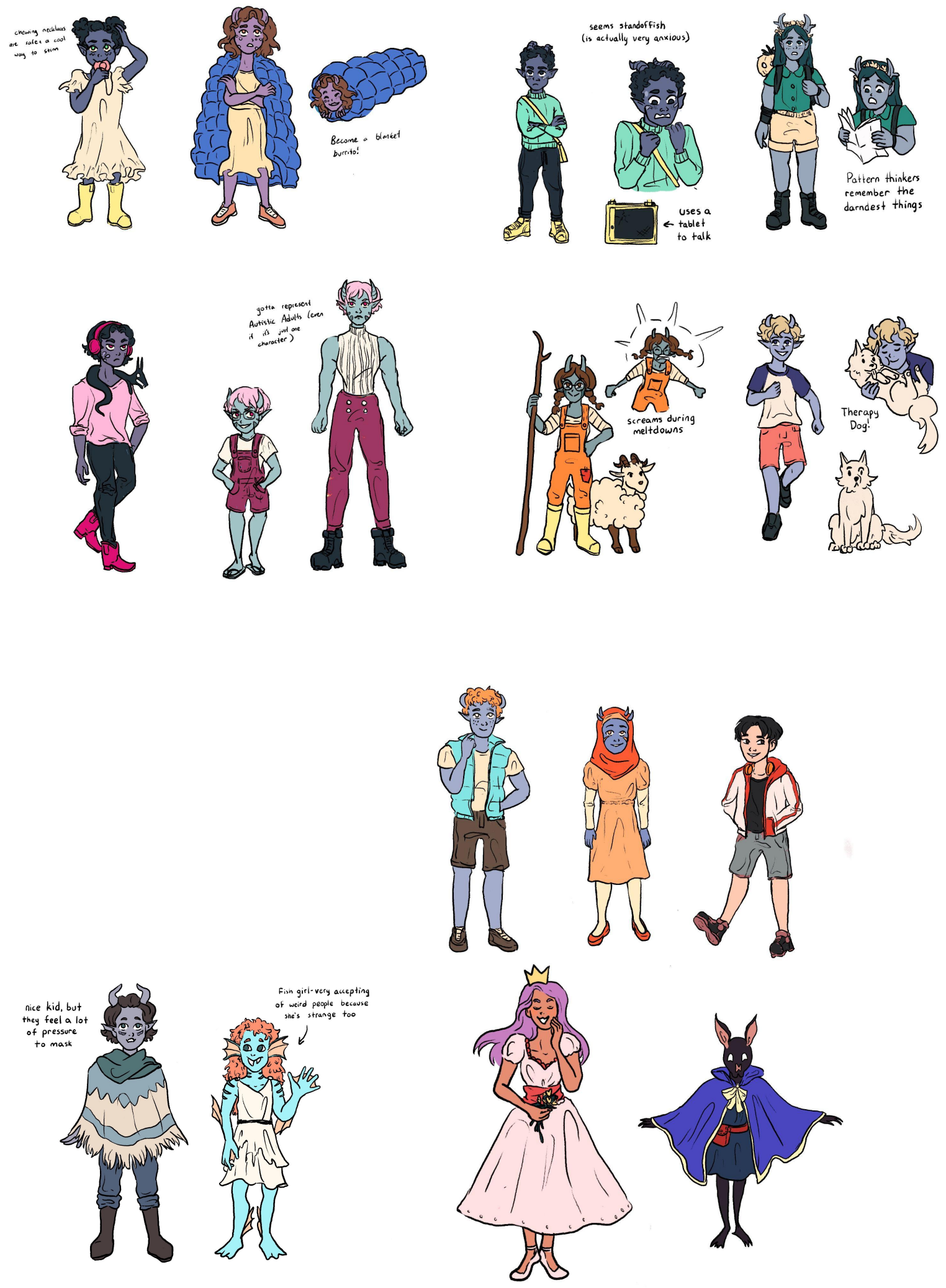

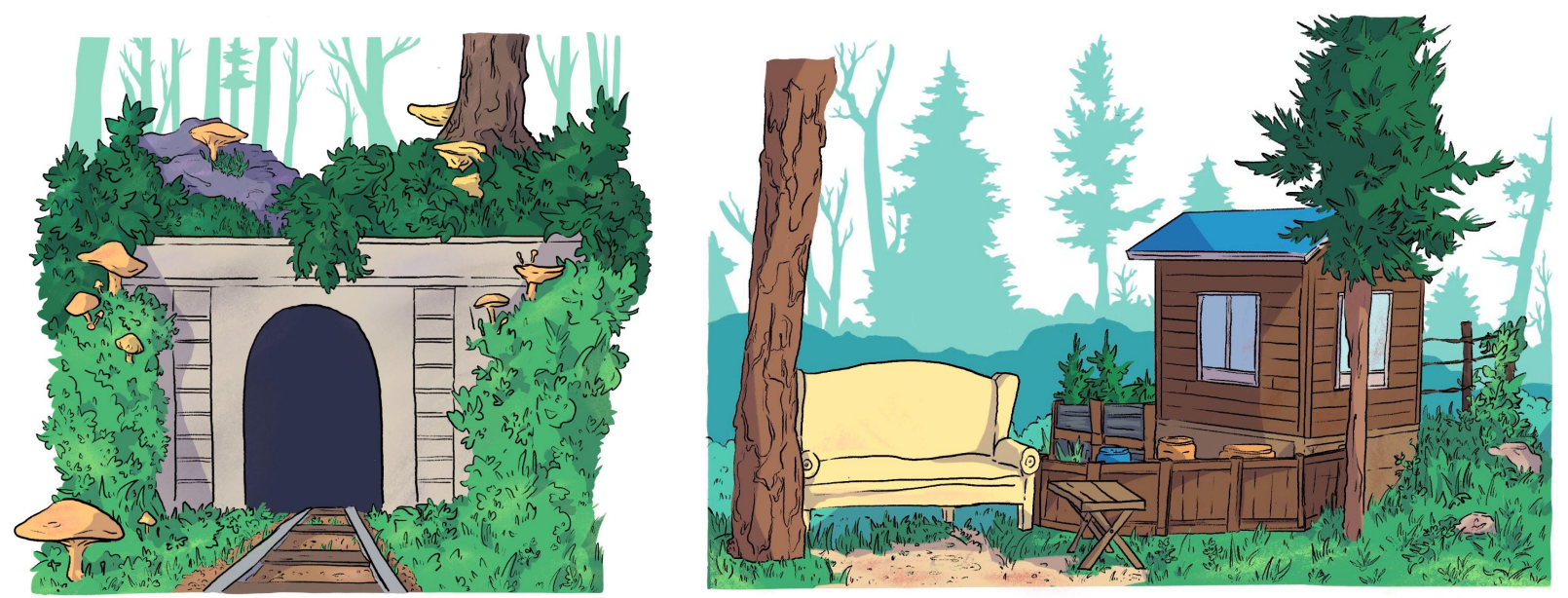

\section{The Book}

What l've developed by the end of this term is a proof of concept that can be sent off to a publisher. Upon acceptance I would like to render these pages in full color similar to the concept art, but the composition, narrative, and characters would remain largely the same. 


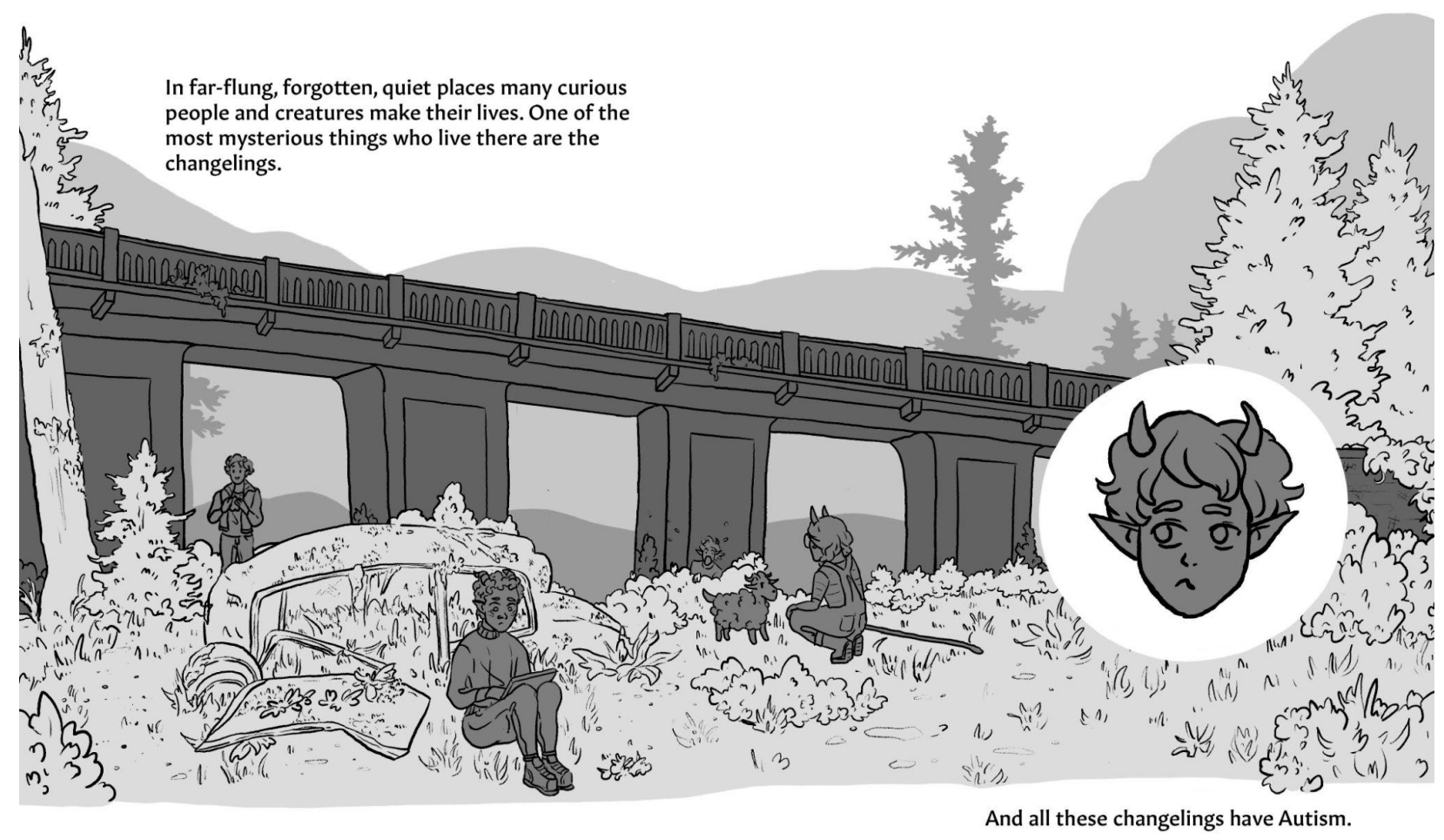

This first spread is an introduction to the changelings and their world. I opened up the book with a splash spread that shows these characters in a quiet, candid moment. Before launching into the details, I thought that it would be appropriate to set a general tone for the narrative and setting. 

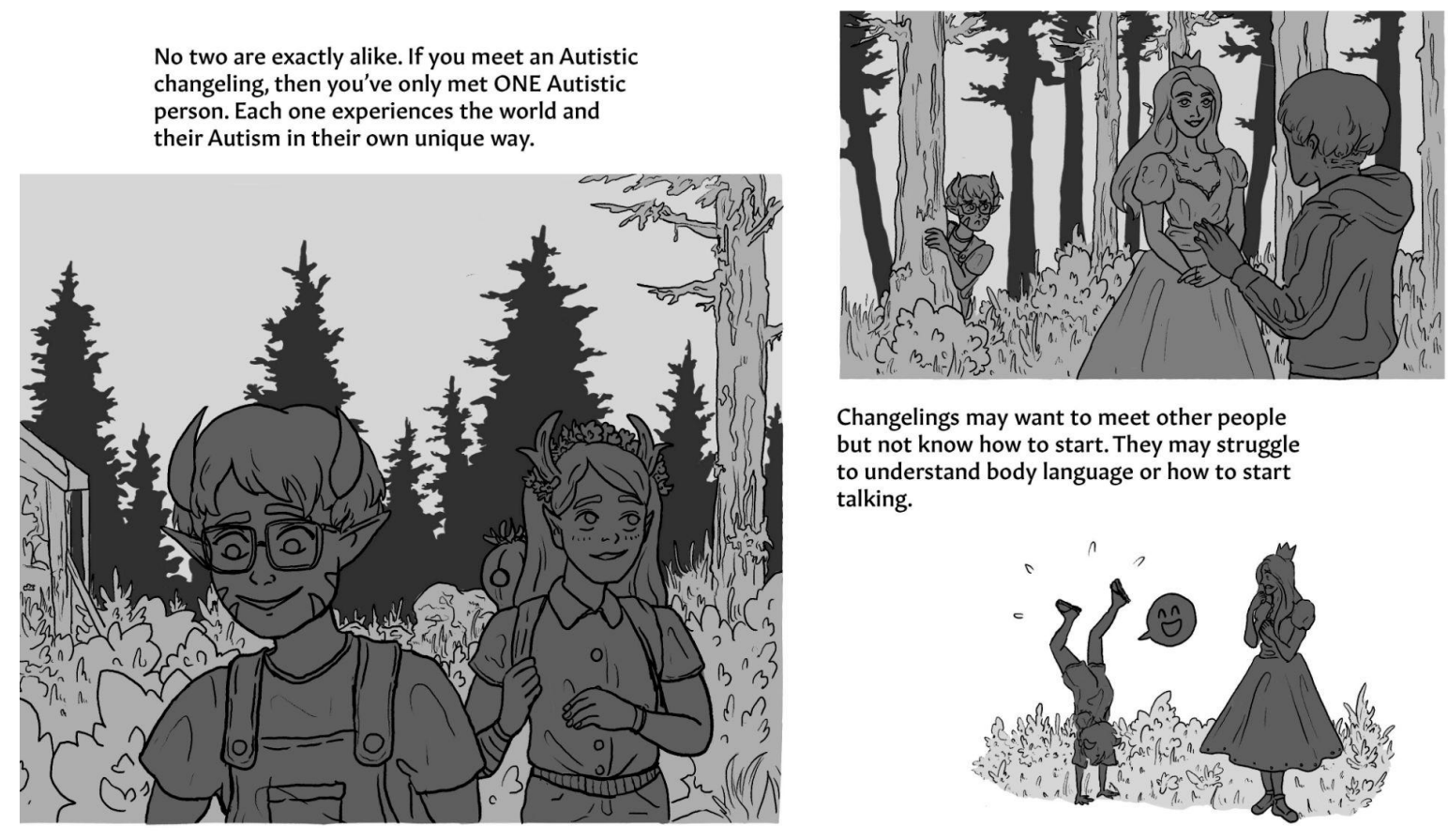

\begin{abstract}
Changelings may want to meet other people but not know how to start. They may struggle to understand body language or how to start talking.
\end{abstract}

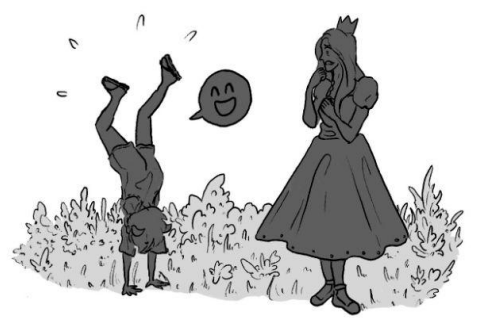

Sometimes others think they act strangely or a little rude, because they don't know the polite thing to do.

The left page highlighted one of the most important maxims in the Autistic community: when you meet an Autistic person, you've only met one Autistic person. This stresses the broad range of needs and abilities that exist on the spectrum, an idea that the rest of this book will support. The right page touches on the shenanigans that often happen to a group that struggles with social cues. This is one of the definitive parts of the Autistic experience: an impaired ability to interpret verbal and nonverbal communication. 


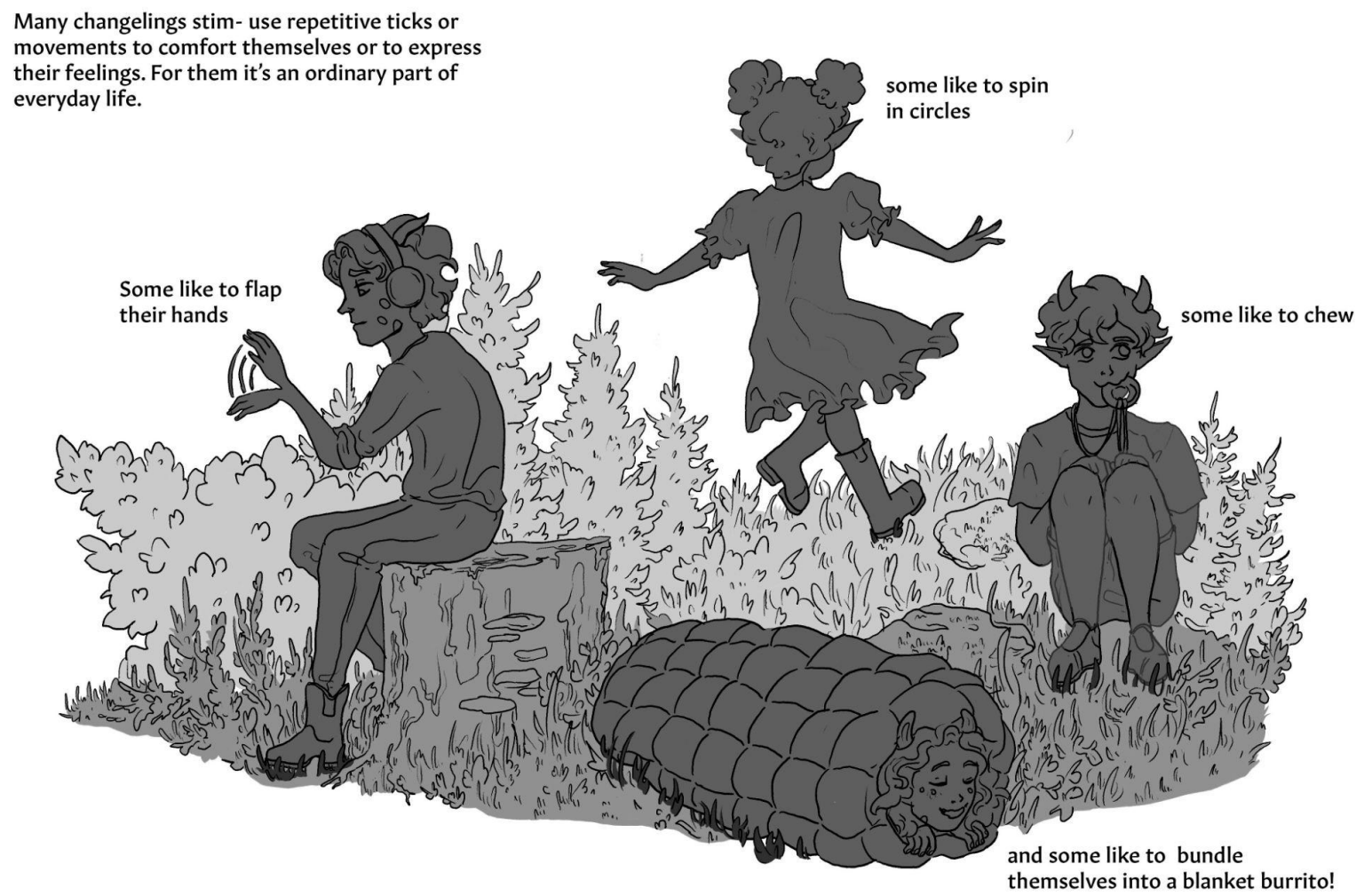

Stimming-repetitive, consistent movements- are a way for Autistic people to express emotions and to calm themselves. Self advocates assert that this is a healthy behavior, and should not be derided or suppressed. I agree with this view, and used this spread to highlight some common stims and how unremarkable they are once they are understood properly. 

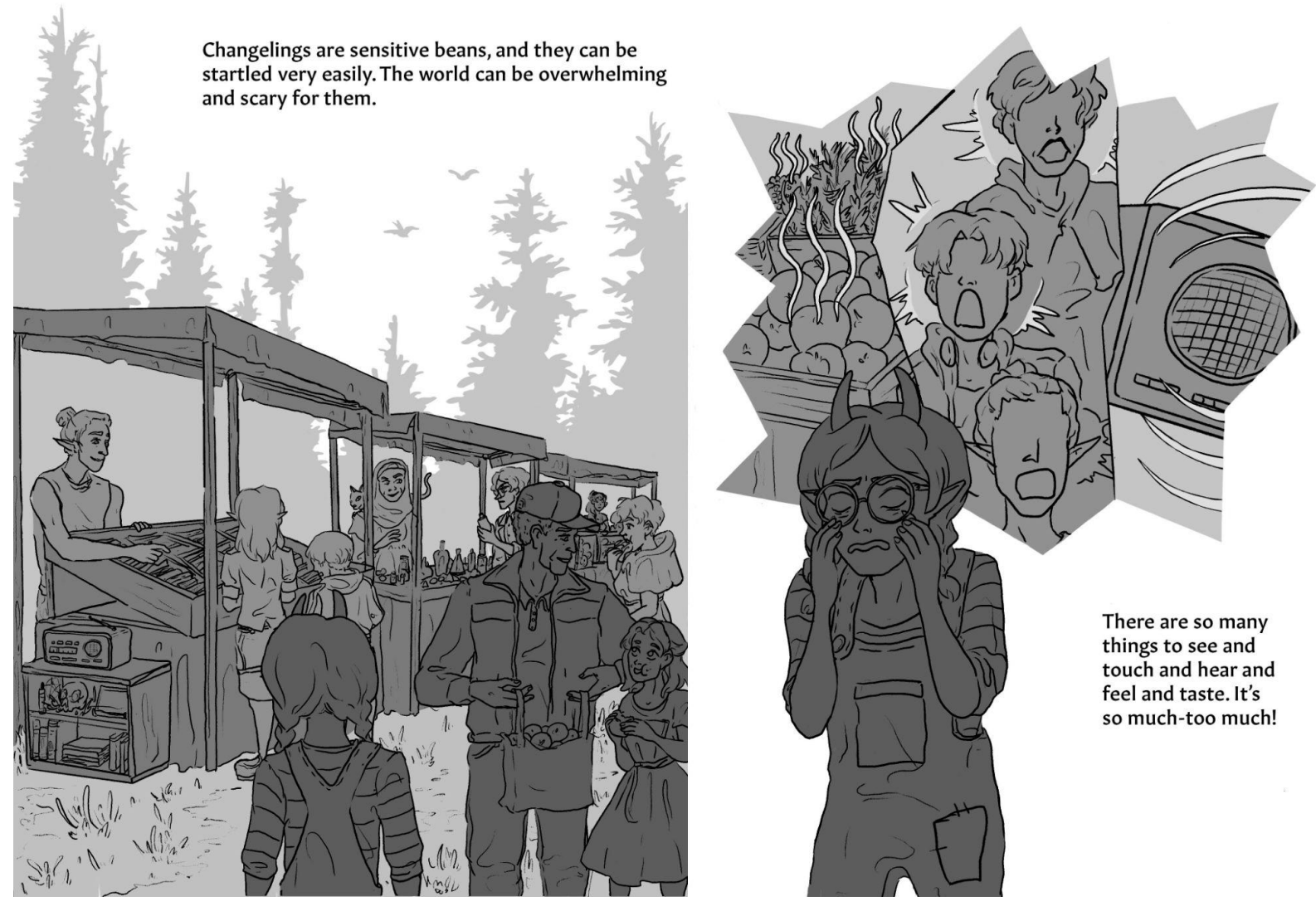

Sensory overload is what is taking place across these two pages. Many Autistic people have heightened senses, and this spread shows how even a simple trip to the market can trigger this. I wanted to show some of the more unpleasant parts of living with Autism to keep this story from being overly sugar-coated. Situations like sensory overload can have an enormous impact on Autistic peoples' ability to function, a daily struggle that is important to recognize. 


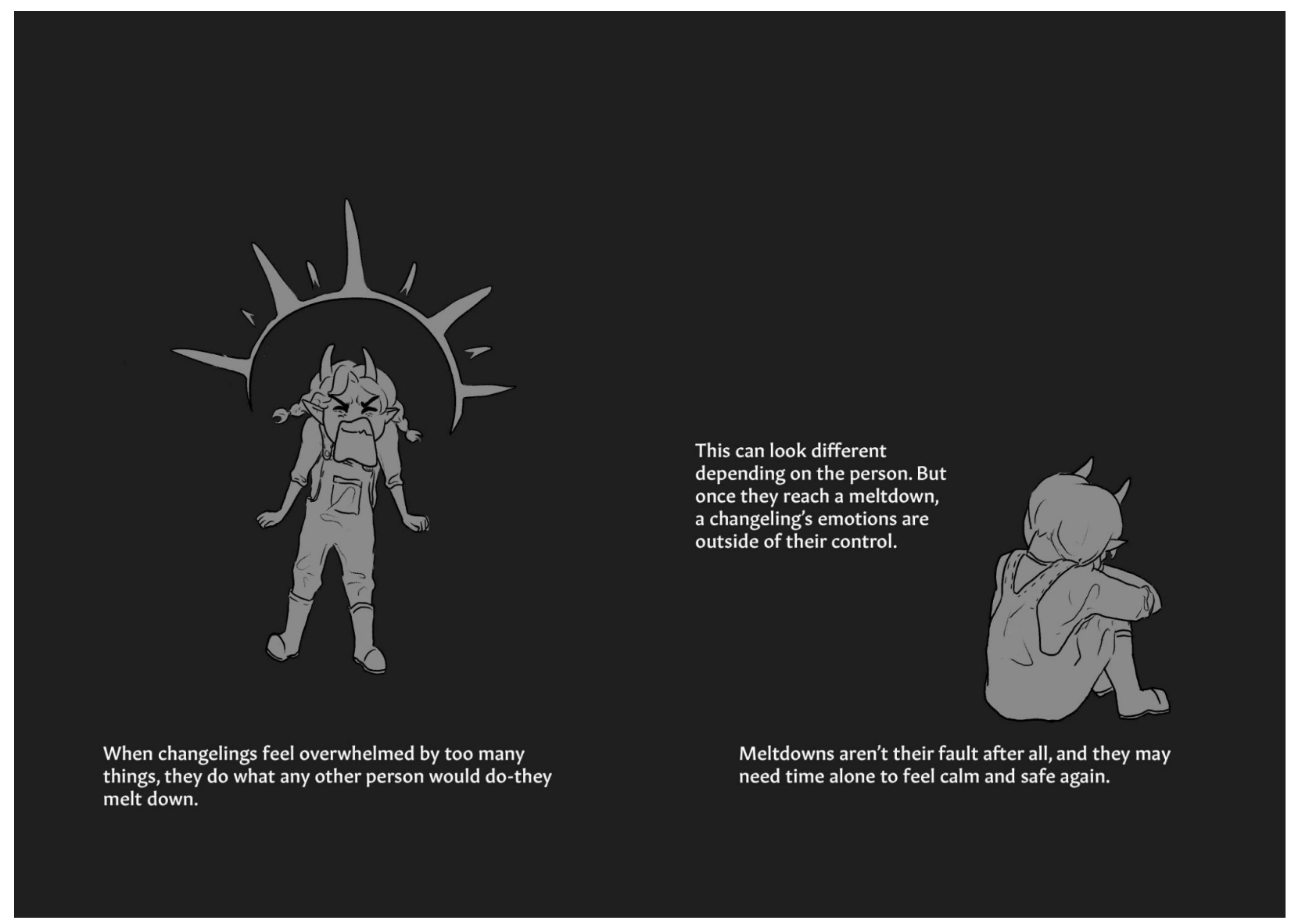

Meltdowns are intimidating to observe, and even more terrifying to experience

firsthand. Dealing with this stage of distress is beyond the scope of a children's book, so I decided to simply explain what happens when an Autistic person does this. Meltdowns are often treated as either a comedic spectacle or as shocking, fear-mongering material on social media. To stay away from these portrayals, I tried to encourage empathy by noting how Autistic people lose control of their emotions during meltdowns, and commenting how even a neurotypical person may react the same way if they experienced this kind of sensory overload. 


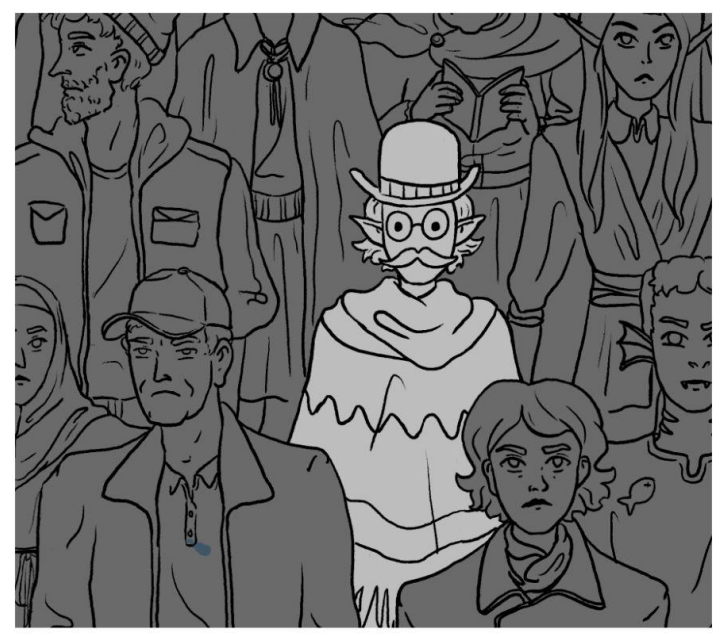

Sometimes changelings "mask," or act so they can fit into a more "normal" crowd.

While this can work, it is tiring and emotionally

painful.
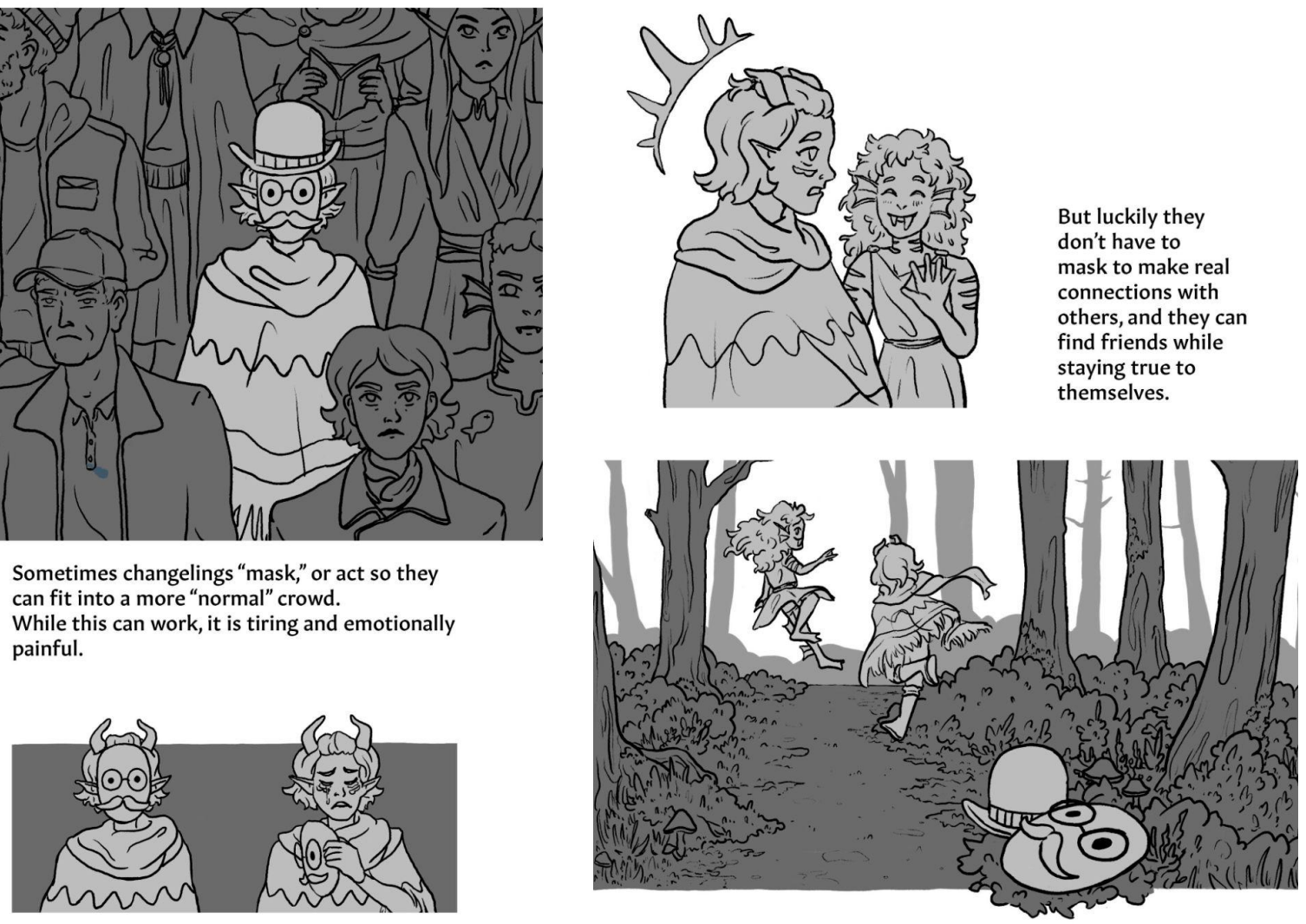

These two pages are all about the pressures Autistic people face to conform to neurotypical behavior patterns. The community calls this 'masking' and I interpreted it very literally here. While these pressures are real, I also wanted to send a hopeful message to readers, and encourage them to express their authentic selves. 
Changelings feel their emotions very strongly. Some don't think that they feel anything, but this isn't true.

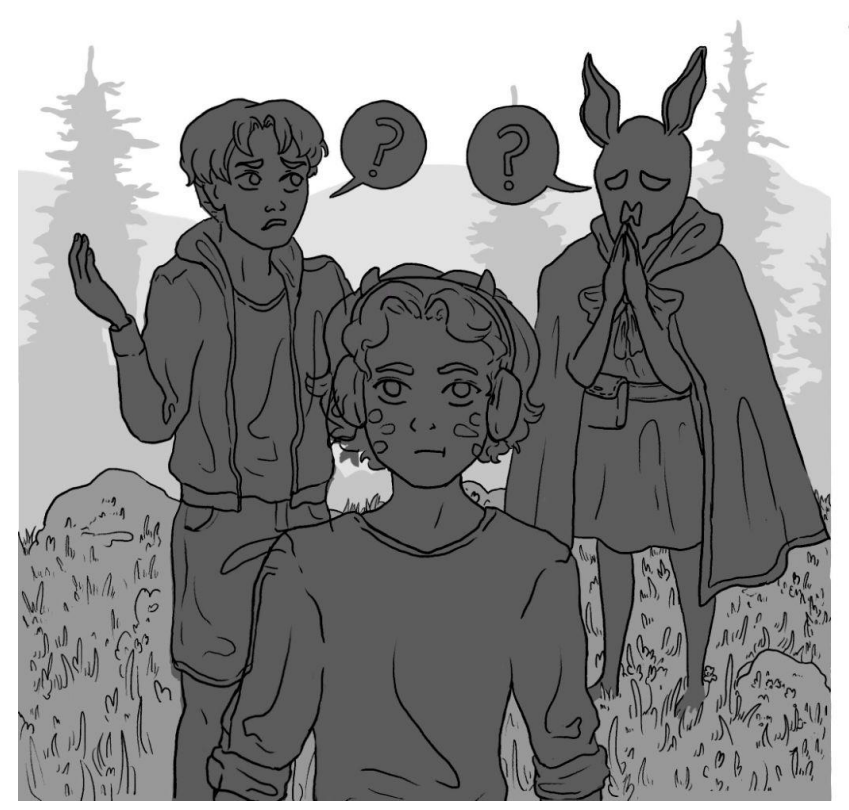

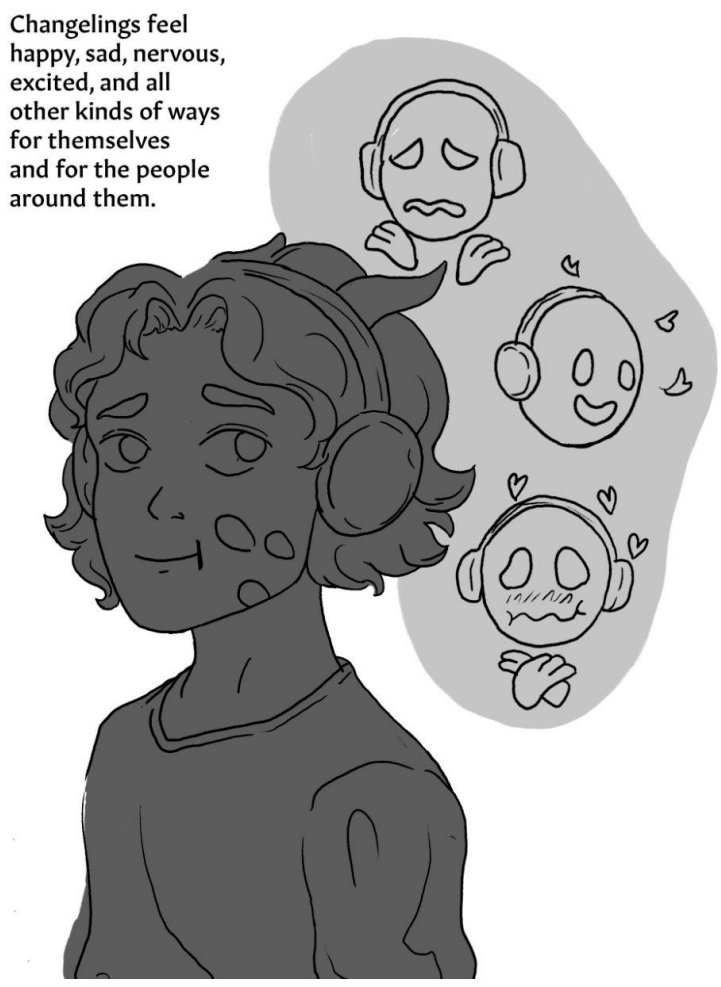

These pages deal with the belief that Autistic people lack emotions and behave

like automatons. They actually feel fierce, overwhelming emotions, but this doesn't always translate to the body language and facial expressions often associated with these feelings. I wanted to share this knowledge by showing a fairly subdued character who tends to keep these feelings to themselves. 


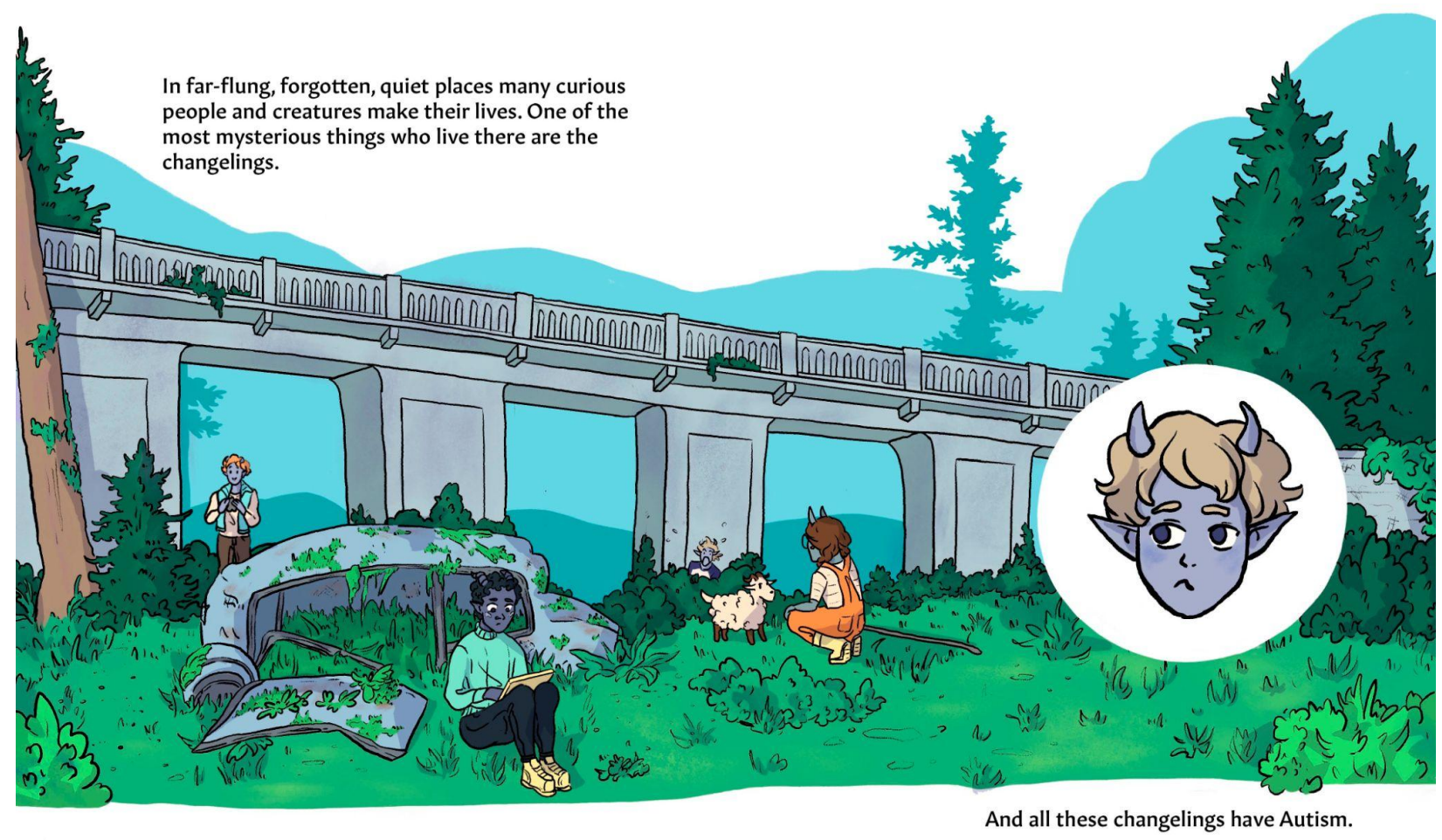

This is an example of the book in its fully rendered, colored version.

\section{$\underline{\text { Reflections }}$}

At the end of this project I've realized two critical takeaways. The first is that it is vital for content creators to include marginalized groups in their work. Whether this means people from different backgrounds or disabled people, their inclusion can hold incredible influences on audiences and their status in their communities. The second is that it's alright for these creators to make mistakes when attempting this, as long as they treat this as an opportunity to grow. Humans have been misrepresenting each other for centuries, and will continue to stumble as they muddle through their creative 
projects. But by reflecting on past work and the reasons behind it, we as designers, writers, and illustrators can create a world that accepts disabled people, and even cherishes them for their differences. 


\section{Works Cited}

Bever, Lindsey. “How a 'Sesame Street' Muppet became embroiled in a controversy over autism." The Washington Post, 19 September 2019. Web.

Hoopman, Kathy. All Cats have Asperger's Syndrome. Jessica Kingsley Publishers, 2006. Print.

Pennell, Ashley et al. Respectful Representations of Disability in Picture Books. Reading Teacher, vol. 71, no. 4, Jan. 2018. pp. 411-419.

Prochnow, Alexandria. "An Analysis of Autism through Media Representation.” The Institute of General Semantics: A Review of General Semantics, Vol. 71, no. 2, April 2014. pp. 133-149.

Scheffer, Edith. Asperger's Children: The Origins of Autism in Nazi Vienna. New York: WW Norton \& Company, 2018. Print.

Zadrozny, Brandy. "Parents are poisoning their children with bleach to 'cure' autism. These moms are trying to stop it." NBC News, 21 May 2019. Web. 